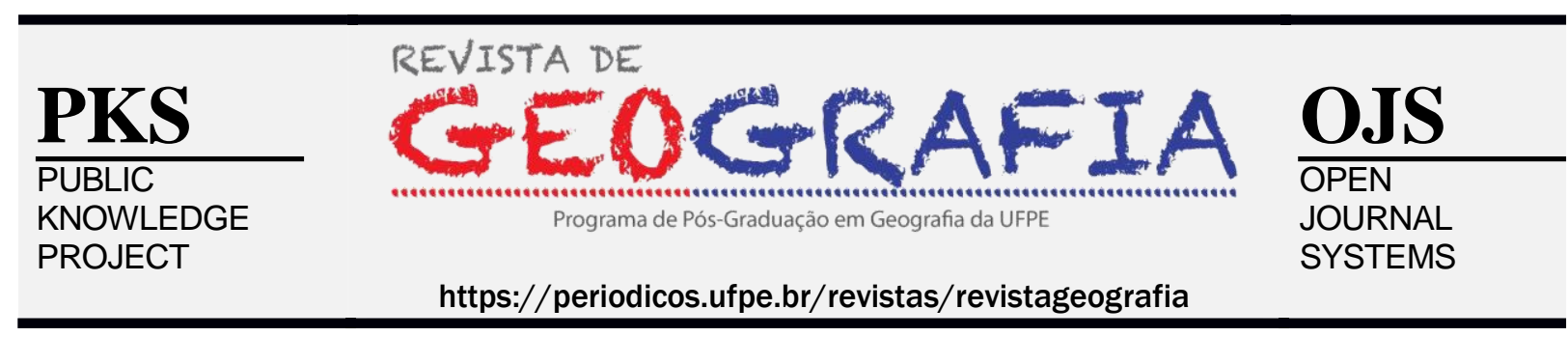

\title{
REFLEXÕES SOBRE A CRIAÇÃO DAS UNIDADES DE CONSERVAÇÃO NO BRASIL E O SISTEMA NACIONAL DE UNIDADES DE CONSERVAÇÃO
}

\author{
Autor ${ }^{1}$ Anderson José da Silva Fonseca, Autor ${ }^{2}$ Helena Paula de Barros Silva, \\ Autor ${ }^{3}$ Rosany Carvalho Locio de Albuquerque
}

${ }^{1}$ Universidade Federal de Pernambuco. E-mail:anderson.profgeo86@gmail.com

${ }^{2}$ Universidade de Pernambuco - Campus Mata Norte.E-mail: helena.silva@upe.br

${ }^{3}$ Prefeitura de Olinda - Secretaria Executiva de Planejamento Ambiental.E-mail: rosanilocio@yahoo.com.br

Artigo recebido em 23/02/2019 e aceito em 25/11/2019

\begin{abstract}
RESUMO
A preocupação em preservar os ambientes naturais ganhou mais fôlego no século passado, através da elaboração de dispositivos legais que instituíram espaços, tanto de proteção integral como de uso sustentável. No Brasil, o diálogo ambiental se iniciou a partir da promulgação do Código de Caça e Pesca e de demais dispositivos legais. Assim, os espaços territoriais especialmente protegidos foram instituídos a partir da constituição de 1988, efetivando a conservação dessas áreas. Este artigo tem como objetivo analisar, através do levantamento de leis e de uma revisão bibliográfica a necessidade de instituir lugares que visem à proteção integral e/ou sustentável de florestas no território nacional. Foi utilizada uma metodologia baseada na interpretação da literatura específica que trata do tema: Constituição Federal de 1988 - art. 225, Lei 9.985/00 - Sistema Nacional de Unidades de Conservação e de alguns autores do direito ambiental que tratam sobre unidades de conservação. Conclui-se que, mesmo com uma vasta legislação e organizações que trabalham diretamente com a conservação florestal, ainda há muitos entraves para que haja uma efetivação daquilo que existe na lei com a prática ambiental.
\end{abstract}

Palavras-chave: SNUC; constituição federal; unidades de conservação; florestas.

\section{REFLECTIONS ON CREATION OF CONSERVATION UNITS IN BRAZIL AND THE NATIONAL SYSTEM OF CONSERVATION UNITS}

\begin{abstract}
The preoccupation with preserving natural environments has added to the past, through the creation of legal devices that instigated spaces for both integral protection and sustainable use. In Brazil, the environmental dialogue was initiated by the promulgation of the Code of Hunting and Fishing and Legal Optics. Thus, the territorial territories were protected were instituted as of the 1988 constitution, effecting the cause of these areas. The objective of this article is to analyze, through law - making and a bibliographic review, the need to create sites that aim at the integral and sustainable protection of forests in the national territory. It was based a methodology based on the interpretation of the literature that deals with the theme: Federal Constitution of 1988 - art. 22, Law 9.985/00 - National System of Conservation Units and main authors of environmental law. It concludes that, even with a vast body of legislation and organizations working directly with the forest, there is still much to be done to ensure that there is an enforcement of what exists in law with an environmental practice. Keywords: SNUC;federal constitution; protected areas; forests.
\end{abstract}




\section{INTRODUÇÃO}

Historicamente, o homem passou de sujeito passivo dos fenômenos naturais para ser modificador dela, passando a adquirir técnicas de sobrevivência em meio à natureza, assim, o ambiente natural começa a ser modificado. Tal modificação passou por milênios de degradação ambiental, despertando somente no último século o interesse dos países em criar leis para a proteção dos ambientes naturais.

Essa ideia se espalha pelo mundo e chega aos países emergentes, já no século XX, a exemplo no Brasil, quando estava ainda no período da Era Vargas, onde o expansionismo industrial se acelerava no país, ocasionando a derrubada de vegetação e consequentemente o início de um desequilíbrio ambiental (JUNIOR, et al, 2009).

A partir desse período, no Brasil o debate ambiental começa a ganhar força com a instituição do Código de Caça e Pesca e do Código Florestal, ambos de janeiro de 1934, onde em seus artigos abordam o interesse da defesa da fauna e flora nacional. Com o surgimento do Código Florestal vieram prerrogativas para a criação de parques de preservação natural, iniciando a partir de então as políticas para áreas protegidas (DIEGUES, 2001). Assim, as primeiras áreas protegidas começaram a surgir no país, como a Floresta Nacional do ApodiAraripe no Cerará.

Em 1965 puderam ser observadas no Código Florestal algumas mudanças, tais como a inclusão de Áreas de Proteção Permanente e o Programa Homem e a Biosfera, em 1976, criando as Reservas da Biosfera objetivando a conservação da biodiversidade e dos recursos naturais (DIAS, 2011). Nos anos 1980 foi criada a atual constituição vigente, conhecida também como “Constituição Verde" (MACEDO, 2014), pois, ela dá destaque em seus artigos, ao meio ambiente como bem comum de todos, instituindo princípios de sustentabilidade e de Reserva Legal.

A partir do artigo 225, da Constituição Federal de 1988 (CF/88), § $1^{\circ}$, III, incube ao poder público a definição de espaços territoriais a serem especialmente protegidos, onde mais tarde muitos destes lugares serão chamados de Unidades de Conservação a parir da lei 9.985 de 18 de julho de 2000, lei do Sistema Nacional de Unidades de Conservação - SNUC. Assim, não só no âmbito federal, mas cada estado da federação tem a incumbência de criar o seu sistema de unidades de conservação em conjunto com o sistema nacional. 
Os Sistemas Estaduais de Unidades de Conservação têm a incumbência de tratar de todos os espaços territoriais especialmente protegidos do âmbito estadual, amparados pela lei nacional que define as unidades de conservação federais. A descentralização da gestão destas unidades é o que pode garantir uma melhor gestão quanto à proteção destes lugares, onde a participação da população deve ser levada em conta, junto com a equipe gestora. Assim, as parcerias público-privadas devem ser o ponto de apoio principal para garantir a eficácia na gestão das UC.

\section{ESPAÇOS TERRITORIAIS ESPECIALMENTE PROTEGIDOS E A CONSTITUIÇÃO FEDERAL DE 1988}

Segundo a Constituição Federal de 1988, em seu artigo 225, caput, afirma que todos têm direito ao meio ambiente ecologicamente equilibrado, bem de uso comum do povo e essencial à sadia qualidade de vida. E continua em seu discurso incumbindo o poder público e a coletividade de defender e preservar o meio ambiente garantindo seu uso não somente para as civilizações atuais, mas que seja ofertado também para as gerações futuras.

Não é de hoje que existe essa preocupação, tanto é que a legislação, onde contemporaneamente é classificada em três gerações, por fim, modernamente, protege-se como direito de terceira geração constitucionalmente os chamados direito de solidariedade ou fraternidade que englobam um direito ao meio ambiente equilibrado, uma saldável qualidade de vida, ao progresso, a paz, a autodeterminação dos povos e a outros direitos difusos. (TOLOMEI, 2005).

Segundo Milaré (2007), no artigo 225, no qual diz "bem de uso comum do povo" afirma que esse bem difuso deve ser objeto de proteção do Estado e da própria sociedade para usufruto de toda a nação. Para Di Pietro (2014), explica que se considera bens de uso comum do povo, aqueles que, por determinação legal ou por sua própria natureza, podem ser utilizados por todos em igualdade de condições.

O Supremo Tribunal Federal - STF - afirma que o direito a integridade do meio ambiente - típico direito de terceira geração - constitui prerrogativa jurídica de titularidade coletiva, refletindo, dentro do processo de afirmação dos direitos humanos, um poder atribuído mais abrangente à própria coletividade social. Isso deixa claro que é de direito do povo o meio ambiente equilibrado, mas para isso é necessário que haja uma participação ativa da sociedade na conservação do ambiente. 
Para isso, cria-se um direito constitucional fundamental ao meio ambiente ecologicamente equilibrado, sendo ele indisponível, pois essa indisponibilidade deve ser feita amparada na Constituição, pelo interesse em manter preservado o meio ambiente não somente para a geração atual, mas também como garantia para as futuras gerações.

Milaré (2007) afirma que o meio ambiente como uma entidade autônoma é de "bem e uso comum do povo", não pertence a indivíduos isolados, mas pertence a toda coletividade, aonde essa afirmação já vinha consolidada pela lei 6.938/1981 qualificando meio ambiente como patrimônio público a ser necessariamente assegurado e protegido, tendo em vista o uso coletivo.

$\mathrm{O}$ meio ambiente é reputado bem essencial à sadia qualidade de vida. $\mathrm{E}$, cabe ao Poder Público um dever constitucional, geral e positivo, representado por obrigações de fazer e preservar o meio ambiente, tendo sua atuação vinculada (MILARÉ, 2007). A partir da Constituição de 1988 o Poder Público não atua no meio ambiente por seu próprio interesse, mas é determinado pelo legislador maior.

O cidadão também deixa de ser um mero titular passivo de um direito ao meio ambiente equilibrado, mas passa também a ter a titularidade de um dever de defender e preservar junto como Poder Público.

A tutela do meio ambiente, de acordo com o artigo 225 da $\mathrm{CF} / 88$, afirma que a:

Preservação e restauração dos processos ecológicos essenciais; Promoção do manejo ecológico das espécies e ecossistemas; Preservação da biodiversidade e controle das entidades de pesquisa e manipulação de material genético; Definição de espaços territoriais especialmente protegidos; Realização de estudo prévio de Impacto Ambiental; Educação Ambiental; Proteção a Fauna e Flora (MILARÉ, 2007, p. 152 $-168)$.

O Poder Público como principal responsável pela tutela do meio ambiente, de acordo com Antunes (2001) define que:

\begin{abstract}
A preservação é uma obrigação cujos sujeitos passivos são os diversos órgãos públicos especialmente voltados para a referida tarefa ou para aqueles que tenham promovido ou estejam promovendo atividades ambientalmente impactante. [...] $\mathrm{O}$ Estado deve se empenhar em estabelecer processos que permitam a recuperação de ecossistemas degradados, quaisquer que sejam as origens da degradação (ANTUNES, 2001, p. 50).
\end{abstract}

O autor acima reforça a missão do Estado, sendo este o tutelar de direito de proteção e gestão do meio ambiente, a tarefa de preservar o meio ambiente através do seu poder de polícia e definir quais caminhos devem ser trilhados para a recuperação de ecossistemas degradados através de atividades de grande impacto ambiental (ANTUNES, 2001; FIORILLO, 2009). 
No artigo $225, \S 1^{\circ}$, inciso III da atual C.F. define que em todas as unidades da Federação, espaços territoriais e seus componentes a serem especialmente protegidos, sendo a alteração e a supressão permitidas somente através de lei, vedada qualquer utilização que comprometa a integridade dos atributos que justifiquem sua proteção.

O dispositivo legal citado acima delega ao Poder Público a responsabilidade de definir quais serão os locais em seu território de jurisdição que necessitam de proteção especial, por força da determinação constitucional, este deverá definir não só as áreas a serem especialmente protegidas, bem como deverá indicar quais dos elementos existentes no seu interior não merecem proteção especial. (ANTUNES, 2001)

Tais locais os quais necessitam de proteção especial devem ser delimitados. A delimitação de espaços para a preservação de certos atributos naturais é uma prática antiga, que se espalhou por todos os continentes, motivada principalmente por razões socioculturais. (MILARÉ, 2007).

A Constituição Federal de 1988 inovou ao adotar a terminologia "espaço territorial especialmente protegido" para designar uma área sob regime especial de administração, com o objetivo de proteger os atributos ambientais tutelados ao Poder Público (grifo nosso).

Tal competência que é dada ao poder público estende-se a todas as suas esferas União, Estados, Municípios e o Distrito Federal - assim como está na CF/88, no artigo 24, VI, verbis: "Compete a União, Estados, Municípios e o Distrito Federal legislar concorrentemente sobre: florestas, caça, pesca, fauna, conservação da natureza, defesa do solo e dos recursos naturais, proteção do meio ambiente e controle da poluição”.

Os espaços territoriais especialmente protegidos foram incluídos no artigo $9^{\circ}$ da lei 6.938/81 a qual teve seu texto alterado pela lei 7.804/89 que trata da Política Nacional do Meio Ambiente - PNMA - onde tem o seu amparo constitucional através da redação do artigo 225 da C.F.

O artigo $9^{\circ}$, VI, da lei ${ }^{\circ}$ 6.938/81 que dispõe da Política Nacional do Meio Ambiente traz em sua redação tratando dos instrumentos da referida política a "criação de espaços territoriais especialmente protegidos pelo Poder Público federal, estadual e municipal, tais como área de proteção ambiental, de relevante interesse ecológico e reservas extrativista". A alteração dada pela lei 7.804/89 retira o nome extrativista, dando amplo sentido legal. (grifo nosso)

Assim, o regulamento 99.274/ de 6 de junho de 1990 em seu título primeiro que trata da execução da PNMA, mais precisamente o artigo $1^{\circ}$, II, cumpre ao Poder Público nos seus 
diferentes níveis de governo - federal, estadual e municipal - (ANTUNES, 2001), "proteger as áreas representativas de ecossistemas mediante a implantação de unidades de conservação e preservação ecológica” (grifo nosso)

Entende-se que a partir do decreto 99.274 de 1990 os tais espaços territoriais especialmente protegidos que estão dispostos nas redações dos artigos $9^{\circ}$ da PNMA e $225^{\circ}$ da C.F. passam a serem tratados como "Unidade de Conservação" (MILARÉ, 2007)

Dez anos depois surge a lei 9.985/2000 que passa a regulamentar tais áreas especialmente protegidas, denominadas a partir de então de Unidades de Conservação - UC. A lei supracitada não fez qualquer referência a outras áreas naturais protegidas que não àquelas enquadradas no conceito de UC assim como consta no artigo $2^{\circ}$, I, verbis:

\begin{abstract}
espaço territorial e seus recursos ambientais, incluindo as águas jurisdicionais, com características naturais relevantes, legalmente instituído pelo Poder Público, com objetivos de conservação e limites definidos, sob regime especial de administração, ao qual se aplicam garantias adequadas de proteção (LEI 9.985/00, art. 2º I).
\end{abstract}

A partir de então os "territórios especialmente protegidos" passam a ter uma denominação específica e um amparo legal direcionado para a proteção e conservação desses espaços. As Unidades de Conservação, por serem espaços com objetivos diversos, foram necessárias à criação de tipos distintos de categorias (MILARÉ, 2007). Também se faz necessário que haja conjuntos de UC de distintas categorias de manejo que, devidamente ordenados, sejam capazes de alcançar a totalidade dos objetivos de conservação.

Sendo assim, as Unidades de Conservação são divididas em dois grandes grupos, as de proteção integral e as de uso sustentável. O legislador, com o intuito de sistematizar as categorias de manejo das áreas legalmente protegidas e destinadas à conservação de biodiversidade foi regulamentado o artigo $225, \S 1^{\circ}$ e o seu inciso III, instituiu e consolidou o Sistema Nacional de Unidades de Conservação da Natureza, tendo o seu amparo legal na lei

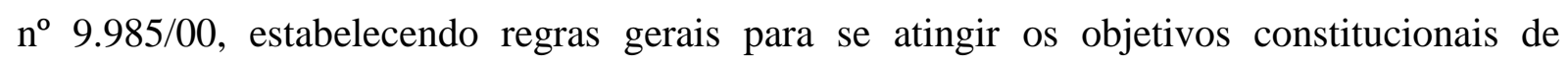
conservação previstos nos incisos I, II e VII do artigo 225 da CF (MILARÉ, 2007).

Em sentido estrito, a partir da promulgação da lei que instituiu o Sistema Nacional de Unidades de Conservação da Natureza - SNUC fica evidente que os aqueles espaços territoriais especialmente protegidos denominados no PNMA ficam restritos somente às categorias de unidades de conservação.

Em seu sentido amplo com legislação distinta e própria ficam as Áreas de Preservação Permanente e as Reservas Florestais Legais amparadas pelo Código Florestal e as Áreas de Proteção Especial pela lei de Parcelamento do Solo Urbano. Todas elas possuem fundamentos 
e finalidades próprias e distintas das unidades de conservação, tomando a cargo do poder público e de toda a sociedade a efetiva participação na conservação destes espaços.

A criação de áreas protegidas e as Unidades de Conservação no Brasil

Após a revolução dos anos 1930, na era Vargas, o Brasil passa por um momento de transformação urbana e industrial e assim, começa a partir deste período uma expansão das atividades industriais e consequentemente a utilização de áreas naturais.

Para regular esse avanço, políticas públicas voltadas para a conservação de áreas naturais começam a ganhar força, implementando assim regras em apoio à preservação de espaços naturais. Frente a este cenário de elaboração de políticas públicas voltadas para a criação e gestão de parques no mundo, no Brasil, esta discussão começa a ganhar força a partir do século $\mathrm{XX}$, porém, assuntos ambientais só ganham destaque político, jurídico e institucional décadas depois.

É na década de 1930 que é aprovado o Código de Caça e Pesca que regulamenta as atividades extrativistas nas áreas consideradas de interesse preservacionista e mais tarde é promulgado o Código Florestal e o Código das Águas. Em 1934 passa a ser de ordem constituinte a conservação ambiental como um princípio básico que deve ser assegurado pelo Estado. O Código Florestal tornou possível o estabelecimento de unidades de conservação no modelo como é conhecido hoje (MEDEIROS et al., 2006 citado por JUNIOR et al., 2009).

Daí começou o surgimento dos primeiros parques brasileiros, como o Parque Nacional do Itatiaia em 1937, dando início efetivo as políticas de gerenciamento de áreas protegidas. (DIEGUES, 2001; JUNIOR et al, 2009).

Outros dois parques foram também estabelecidos nesse período, o Parque Nacional do Iguaçu e da Serra dos Órgãos, ambos os três parques pioneiros citados pertencentes dentro do bioma Mata Atlântica pelo fato de ser uma das maiores florestas tropicais do planeta que começou a ser explorada desde a colonização europeia no Brasil (SILVA, et al., 2005).

A primeira Floresta Nacional foi criada na década de 1940 no estado do Ceará, a Araripe-Apodi, categoria prevista já também no Código Florestal. Dentro do bioma Mata Atlântica merece destaque a implementação da maioria das unidades de conservação, haja vista que este é o principal bioma que mais sofre alterações em sua composição desde o período colonial. 
Os modelos tradicionais de parques norte-americanos são bem distintos dos nacionais. Quando se fala em proteção integral no Brasil, tem-se a ideia de proteger os biomas e ecossistemas próximos aos centros urbanos, onde foram que sofreram mais pressão antrópica. No Brasil, priorizou-se a ocupação de áreas onde havia concentração populacional e de atividades humanas para conservação de ecossistemas remanescentes. Já os norteamericanos são parques distantes dos centros urbanos, buscando proteger as paisagens de um impacto futuro.

As leis ambientais tornaram-se dispositivos de conservação dos parques formados nas áreas densamente povoadas, notadamente na Mata Atlântica, que concentra grande parte das atuais unidades de conservação do país. Na década de 1940 esse cenário não foi tão alterado. As políticas públicas em relação à proteção do meio ambiente se restringiam mais a criação de novas unidades de conservação. No período militar essa visão continuou, mesmo com a ideologia de proteção do território, as florestas ainda eram limitadas à implementação de novas unidades de conservação.

Mesmo com a visão autoritária e burocrática na época da ditadura militar no Brasil, sem dar muita relevância às questões ambientais voltadas para estudos e pesquisas, o mundo, vivendo o período pós-guerra, já mostrava avanços nas políticas públicas quanto à proteção do meio ambiente.

Uma mudança pôde ser observada no Código Florestal foi em 1965, quando houve a definição de área de proteção permanente (APPs), ampliando a proteção definida em lei para florestas de topo de morro, margens de rios, nascentes, encostas íngremes e restingas.

Na década seguinte, em âmbito mundial, as discussões sobre o meio ambiente se tornam mais expressivas, até que em 1968, uma Conferência sobre a conservação e uso racional dos recursos da biosfera estabelece bases para o lançamento de um programa que visava a melhor forma na relação homem-natureza.

Como consequência, o Programa Homem e a Biosfera, a partir de 1976, criou uma rede mundial de áreas protegidas denominadas Reservas da Biosfera. Estas reservas envolvem regiões com ecossistemas terrestres ou costeiros onde objetivam a conservação da biodiversidade com a exploração racional dos recursos naturais (DIAS, 2011).

No Brasil a Mata Atlântica é um dos biomas dentro dessa territorialidade conferida no programa mundial citado, além de abraçar outros biomas nacionais, tais como a Caatinga, o Cerrado, o cinturão verde de São Paulo e a Amazônia Central. 
Ainda nesta época grandes discussões continuaram no mundo sobre a problemática meio ambiente $\mathrm{x}$ homem traçando metas e limites para a melhor utilização dos recursos naturais. Assim, foram surgindo outros programas, como em 1972 o Programa das Nações Unidas sobre o Meio Ambiente (PNUMA), encarregado de monitorar o avanço dos problemas ambientais no mundo.

A partir deste momento começam a surgir no país, paulatinamente, instituições e políticas públicas voltadas ao meio ambiente, como a criação do Instituto Brasileiro de Desenvolvimento Florestal em 1967 que, junto com a Secretaria Especial de Meio Ambiente cuidavam da política ambiental nacional e da gestão das unidades de conservação existentes.

No governo de Geisel, foi lançada a Política Nacional de Meio Ambiente (PNMA) pela lei $n^{\circ} 6.938$ de 31 de agosto de 1981 que constitui também o Sistema Nacional de Meio Ambiente (Sisnama) e o Cadastro de Defesa Ambiental.

O PNMA teve por objetivo a preservação, melhoria e recuperação da qualidade ambiental propícia à vida, no sentido de assegurar condições ao desenvolvimento socioeconômico no Brasil assim como aos interesses da segurança nacional (FIORILLO, 2009). Esses interesses de segurança nacional era o da ditadura militar tendo sido formulado pelas Forças Armadas da época. Pois, o PNMA baseado no Art. $2^{\circ}$ da referida lei que tutela os bens ambientais assim como a proteção da dignidade da vida humana, adaptada aos interesses do Conselho de Segurança Nacional.

Com o estabelecimento da democracia os bens ambientais passaram a ser de uso comum do povo (FIORILLO, 2009) e, ao tomar posse em 1985, o presidente Sarney criou o Ministério do Desenvolvimento Urbano e do Meio Ambiente, sendo que em 1999 passa a se chamar de Ministério do Meio Ambiente, dando-lhe um rol de competências e instrumentos políticos, jurídicos e institucionais de capacidade de gestão ambiental no âmbito nacional (JUNIOR, et al 2009).

Com a Constituição Federal de 1988 trouxe uma grande mudança no cenário político e social do Brasil e no âmbito ambiental não foi diferente. Em seu artigo 225 é garantido a todos os brasileiros o direito ao meio ambiente ecologicamente equilibrado exigindo harmonia em todos os aspectos que compõem o meio ambiente (FIORILLO, 2009).

(FIORILLO, 2009) destaca que tais princípios previstos no artigo 225 da constituição federal brasileira estão também de acordo com o que foi adotado em vários países, fruto de uma necessidade de uma ecologia equilibrada e indicativos do caminho adequado para a proteção ambiental em conformidade com a realidade social e os valores de cada Estado. 
Sendo assim, a política ambiental se consolida de forma determinante na Constituição de 1988, em seu capítulo que especifica sobre o direito ambiental fortalecendo o PNMA, o Sisnama e o Conama. Com a criação do Instituto Brasileiro do Meio Ambiente e dos Recursos Naturais Renováveis (Ibama) em 1989, tornou-se o órgão executor da PNMA que antes era executada por vários órgãos descentralizados. O Ibama tornou-se o fiscalizador das unidades de conservação federais, formulador da política de implantação de unidades de conservação estimulando os órgãos estaduais e municipais ambientais a implantarem suas áreas protegias.

O principal instrumento jurídico que fomenta o trabalho de fiscalização, gestão e monitoramento de unidades de conservação foi com a lei 9.985/00 que criou o Sistema Nacional de Unidades de Conservação - SNUC. Fruto de um trabalho que perdurou durante anos, desde o final dos anos 1970, alvo de críticas de preservacionistas, movimentos ligados às populações tradicionais, proprietários de terras, dentre outros que obtinham relativo interesse nas áreas que por ventura passariam a ser de interesse público de preservar.

Os espaços territoriais especialmente protegidos (JUNIOR et al, 2009; FIORILLO, 2009), segundo o artigo 225, parágrafo primeiro, inciso terceiro da Constituição Federal de 1988 (CF/88) estabelece que compete ao Poder Público o dever de definir em todas as unidades de federação espações territoriais e seus componentes a serem especialmente protegidos.

A lei 6.938/81 que instituiu a PNMA foi quase que totalmente absolvida pela CF/88 determina que tais espaços territoriais especialmente protegidos sejam instrumentos da Política Nacional do Meio Ambiente. Os espaços especialmente protegidos podem estar localizados em áreas públicas ou privadas. Sabe-se que atualmente as unidades de conservação estão localizadas em áreas públicas e privadas. Muitas unidades de conservação situadas em áreas urbanas são de propriedade privada. Por serem espaços dotados de atributos ambientais significativos, merecem um tratamento diferenciado e especial, porque, uma vez assim declarados, sujeitar-se-ão ao regime jurídico de interesse público (FIORILLO, 2009).

A criação do SNUC possibilitou a integração na forma de gestão das unidades de diferentes categorias e também de diferentes esferas de governo (e mesmo particulares), criando um sistema que pode ser coletivamente planejado (JUNIOR, et al 2009).

O SNUC, segundo o Ministério do Meio Ambiente (2016), afirma que é o conjunto de unidades de conservação federais, estaduais e municipais. Composto por doze categorias de UC cujos objetivos específicos se diferenciam quanto à forma de proteção. 
De acordo com (FIORILLO, 2009) afirma que:

\begin{abstract}
As unidades de conservação, criadas por ato do Poder Público, fazem parte do Sistema Nacional de Unidades de Conservação da Natureza e são constituídas pelo conjunto de unidades de conservação federais, estaduais e municipais de acordo com o disposto na referida Lei n. 9.985/00. Divididas em dois grupos, a saber, as Unidades de Proteção integral (cujo objetivo básico é preservar a natureza, sendo admitido apenas o uso indireto dos seus recursos naturais salvo exceções previstas na própria lei ora mencionada) e as Unidades de Uso Sustentável (cujo objetivo básico é compatibilizar a conservação da natureza com o uso sustentável de parcelas integrantes do SNUC) passaram, por força de lei, a ter composição bem delimitada com objetivos fixados pela norma (FIORILLO, 2009, p. 153).
\end{abstract}

Assim como foi dito pelo autor acima, as unidades de conservação são criadas a partir de um sistema que engloba em dois grupos distintos diferentes tipos de categorias de espaços territoriais especialmente protegidos.

Dentre as que estão no rol de proteção integral a sua utilização só é permitida através de exceções permitidas em lei. Para a utilização destas áreas é quase sempre que necessária a autorização do órgão gestor competente para a realização da atividade prevista em lei.

A ideia de proteção neste grupo é de manter a integridade das espécies que estão ameaçadas de extinção, tanto de fauna quanto de flora. Nas unidades de conservação de uso sustentável as restrições não são tão incisivas quanto no outro grupo. Seu uso é permitido, porém também é regido por exceções que são previstas em lei. Neste grupo estão dispostas categorias que a sua utilização varia de uma para outra, dependendo da sua função social.

A formação de conselhos gestores para a gestão das unidades de conservação traz o controle social para dentro da unidade de conservação. Na criação de uma unidade de conservação, o órgão gestor deve convocar a população para a ouvida de seus interesses, principalmente se se tratar de UC de uso sustentável.

Conflitos sobre o uso da terra é o que mais se encontra nas tomadas de decisão quanto à ouvida da população na criação de uma unidade de conservação. A partir do momento em que a criação de áreas protegidas influencia o ordenamento territorial, gera processos conflituosos. Esse ordenamento, porém, é essencial na busca de desenvolvimento social com justiça e conservação ambiental.

Para minimizar mais esses conflitos e fazer com que estado e sociedade possam debater no tocante aos objetivos das unidades de conservação em sua criação, Organizações Não-Governamentais, ONGs tem um papel positivo de intervenção nesse aspecto levando às pautas com o governo as intenções da sociedade em geral. 
(JUNIOR, et al 2009) defendem que as ONGs ao apoiar os interesses do povo vão de contra os interesses neoliberais políticos que possam permear a criação de uma unidade de conservação, assim:

Muitas das instituições surgidas nesse movimento estão voltadas para a defesa de minorias e de lutas políticas tradicionalmente caras à Esquerda, incluindo justiça social, direitos humanos e distribuição de renda, além da conservação ambiental associada ao desenvolvimento de comunidades de baixa renda. Portanto, são instituições críticas em relação ao sistema neoliberal. (JUNIOR, et al, 2009, p. 51).

As ONGs ambientalistas são de natureza supranacionais e seu modo de operação é globalizante (DIAS, 2011). Estas organizações possuem um papel fundamental na estrutura e organização de gestão ambiental em todos os sentidos. Não somente pelo âmbito de conservar florestas, mas, na preservação e conservação do meio ambiente como um todo.

Segundo (DIAS, 2011) existem ONGs de todos os tamanhos e áreas de influência. Podemos encontrar aquelas que têm atuação localizada, com poucos afiliados e recursos mínimos, e encontraremos outras que apresentam uma ação global, com milhares de filiados e doadores, com recursos imensos.

O mesmo autor ainda afirma que tais organizações ambientais em seu âmbito de atuação não se limitam às fronteiras geográficas de países e territórios, mas que têm alcance global, toda vez que seu objetivo é a proteção do meio ambiente. O GreenPeace, por exemplo, apresenta uma territorialidade descontínua em sua representação em 21 países além de atuar em muitos outros formando ONGs ecológicas, atuando solidariamente.

A participação de tais organizações não governamentais ecológicas houve um aumento da participação dos cidadãos no enfrentamento dos problemas locais, o que levou a entender melhor o significado da necessidade de se organizar em comunidade para uma ação mais eficaz na proteção do meio ambiente como um todo, não somente dos recursos ecológicos.

Esta mesma sociedade civil organizou-se rapidamente, surgindo um número incontável de organizações não governamentais com atuação ambiental que passaram a atuar em temas pontuais relacionados com o meio ambiente, inclusive os relacionados às florestas (DIAS, 2011). Essa nova realidade implica numa radical mudança de atitude por parte das organizações do setor privado e público da economia, que têm cada vez mais de levar em conta a opinião pública quando se trata de questões ambientais. Assim, a eficiência apresentada por muitas dessas instituições, mesmo quando estão atuando em ambientes de 
luta pela sobrevivência, também as tornam instrumentos importantes de ação política na sociedade.

\section{CONSIDERAÇÕES FINAIS}

O discurso ambiental no Brasil tem ganhado força a partir da segunda metade do século passado, a partir da promulgação de institutos legais, como o código de Caça e Pesca, tomando como base a legislação que já existia em países desenvolvidos.

A criação de parques como alternativa de manter preservados ambientes naturais e de inclusão da sociedade no processo de conservação destes espaços é uma realidade antiga em países industrializados, como nos Estados Unidos, com a criação dos Wilderness. Deste modo, a ideia de parques e espaços protegidos começa a ganhar força em vários países do mundo, inclusive o Brasil.

Somente décadas depois, nos anos de 1930, na Era Vargas, que no Brasil, frente aos avanços industriais que ocorria no mundo, o debate ambiental começa a ganhar força, com a instituição do Código Florestal, visando à proteção dos biomas que já vinham sofrendo degradação desde o período colonial no país, tais como a Mata Atlântica e a Caatinga. Assim, os parques nacionais foram instituídos, como o Parque de Itatiaia, dentre outros. Portanto, a política ambiental no país foi crescendo, com a instituição de organismos que puderam garantir a gestão de espaços protegidos.

Foi na Constituição Federal de 1988, conhecida também, ecologicamente falando, como "constituição verde", que a proteção quanto ao meio ambiente equilibrado ganhou força constitucional, instituindo os "espaços territoriais especialmente protegidos", lugares estes que necessitavam de mais atenção do poder público e da sociedade civil quanto à sua conservação.

Partindo desse ideal constitucional de preservação, décadas depois foi instituído o Sistema Nacional de Unidades de Conservação, garantido assim que os espaços territoriais especialmente protegidos na Constituição pudessem ser chamados de Unidades de Conservação da Natureza. A partir de então, o poder público passa a ter a tutela destes locais, tendo o papel centralizador na gestão destas UC, agindo de modo descentralizador, delegando aos estados e municípios a função de gerir as unidades de conservação existentes no país.

Essa descentralização é uma das medidas mais eficaz para que haja uma efetiva participação da sociedade na gestão das unidades de conservação. Existem UC no âmbito 
federal, estadual e municipal, onde em cada uma delas, em seu plano de manejo, a comunidade deve ser ouvida e participar ativamente de todas as decisões tomadas quanto à administração destas unidades. Organizações Não-Governamentais são exemplos de cooperativas que deveriam trabalhar de uma forma mais ativa, incluindo a população local no processo de tomada de decisão, porém, muitas delas são alvo de partidarismo, levando em consideração mais os interesses próprios de governo do que os sociais e comunitários.

Para uma gestão mais democratizada das UC no país, deve primeiramente ser levada em conta uma maior fiscalização por parte do poder público para o cumprimento e efetivação do que está na lei e, a partir de então, incluir a sociedade no processo de tomada de decisão na gestão das unidades de conservação do país. A sociedade civil age como um "filtro" entre as esferas públicas e privadas, trazendo recursos da primeira para a segunda. Assim se explica de parte a atuação das ONGs quando buscam recursos públicos para o seu trabalho em defesa do meio ambiente. Essa mediação é importante, pois permite tornar público temas relevantes para a vida de diversas pessoas, o ambientalismo entre eles.

\section{REFERÊNCIAS}

ANTUNES, Paulo de Bessa. Direito Ambiental. $5^{\text {a }}$ ed. Lumen Juris, São Paulo, 2001.

BRASIL. Lei Federal no 6.938 de 31 de agosto de 1981. Dispõe sobre a Política Nacional do Meio Ambiente, seus fins e mecanismos de formulação e aplicação, e dá outras providências. Disponível em: < http://www.planalto.gov.br/ccivil_03/leis/L6938.htm > Acesso em: 18 jan. 2018.

. Lei Federal $\mathbf{n}^{\circ} 9.985$ de 18 de junho de 2000. Institui o Sistema Nacional de Unidades de Conservação da Natureza e dá outras providências. Disponível em: < http://www.planalto.gov.br/ccivil_03/leis/L9985.htm> Acesso em: 10 mar. 2018.

. Lei Federal $n^{\circ}$ 7.804 de 18 de julho de 1989. Altera a Lei $n^{\circ} 6.938$, de 31 de agosto de 1981, que dispõe sobre a Política Nacional do Meio Ambiente, seus fins e mecanismos de formulação e aplicação, a Lei $n^{\circ} 7.735$, de 22 de fevereiro de 1989, a Lei $n^{\circ}$ 6.803, de 2 de julho de 1980, e dá outras providências. Disponível em: < http://www.planalto.gov.br/ccivil_03/leis/L7804.htm> Acesso em 20 abr. 2018.

. Decreto Federal 99/274 de 06 de junho de 1990. Regulamenta a Lei $n^{\circ} 6.902$, de 27 de abril de 1981, e a Lei $n^{\circ}$ 6.938, de 31 de agosto de 1981, que dispõem, respectivamente sobre a criação de Estações Ecológicas e Áreas de Proteção Ambiental e sobre a Política 
Nacional do Meio Ambiente, e dá outras providências. Disponível em:< http://www.planalto.gov.br/ccivil_03/decreto/Antigos/D99274.htm> Acesso em 20 abr. 2018. - Constituição da República Federativa do Brasil. Disponível em:< http://www.planalto.gov.br/ccivil_03/Constituicao/Constituicao.htm> Acesso em: 22 ago. 2018.

DI PIETRO, Maria Sylvia Zanella. Direito Administrativo. 27 Ed. Editora Atlas. São Paulo, 2014.

DIAS, Genebaldo Freire. Educação e Gestão Ambiental. Editora Gaia. São Paulo, 2011. 118 p.

DIEGUES, Antônio Carlos. O mito moderno da natureza intocada. 2. Ed. São Paulo, Hucitec, 1996.

FIORILlO, Celso Antônio Pacheco. Curso de Direito Ambiental Brasileiro. 10 $0^{\mathrm{a}}$ Ed. São Paulo: Saraiva, 2009.

JUNIOR, Castro E; COUTINHO, B. H.; FREITAS, L. E. Gestão da biodiversidade e áreas protegidas. In: GUERRA, Antônio J.T.; COELHO, Maria C. N. Unidades de Conservação: abordagens e características geográficas. Bertrand Brasil. Rio de Janeiro, 2009. p. 25-65.

MACEDO, Roberto F. de. A Constituição Verde. JusBrasil. São Paulo, 2014. Disponível em: < https://ferreiramacedo.jusbrasil.com.br/artigos/159454381/a-constituicao-verde> Acesso em: 30 mar. 2017.

MILARÉ, Édis. Direito do Ambiente: doutrina, Jurisprudência, glossário. $5^{\text {a }}$ Ed. Revista dos Tribunais. São Paulo, 2007.

SILVA, B. B. da; LOPES, G. M.; AZEVEDO, P. V. de. Balanço de radiação em áreas irrigadas utilizando imagens Landsat 5 - TM. Revista Brasileira de Meteorologia, v. 20, n. 2, p. 243-252, 2005.

TOLOMEI, Lucas Britto. A Constituição Federal e o meio ambiente. DireitoNet. São Paulo, 2005. Disponível em: < http://www.direitonet.com.br/artigos/exibir/2092/A-ConstituicaoFederal-e-o-meio-ambiente> Acesso em: 02 mai. 2017. 